\title{
PERBANDINGAN ALGORITMA SVM DAN KNN DALAM MENGKLASIFIKASI KELULUSAN MAHASISWA PADA SUATU MATA KULIAH
}

\author{
Shedriko \\ Teknik Informatika, Universitas Indraprasta PGRI \\ shedriko@gmail.com
}

Submitted March 1, 2021; Revised November 22, 2021; Accepted November26, 2021

\begin{abstract}
Abstrak
Dua algoritma berbeda menggunakan pendekatan yang berbeda pula. Demikian halnya dengan KNN (K-Nearest Neighbour) dan SVM (Support Vector Machine), dimana yang satu melakukan perhitungan berdasarkan kedekatan jarak antar instance sementara yang lainnya melakukan penghitungan berdasarkan eksistensi hyperplane yang menjadi pemisah antar dua kelas yang menjadi hasilnya. Dengan menggunakan data train yang memiliki beberapa data anomali atau noise, berdasarkan penilaian nyata di lapangan yang umumnya diberikan dosen kepada mahasiswa terhadap hasil lulus atau tidak lulus dari suatu mata kuliah, penelitian ini mendapatkan pembeda antara dua algoritma tersebut. Penelitian dilakukan di Universitas XYZ terhadap mata kuliah "Pengantar Teknologi Informasi". Dengan bantuan software Orange Data Mining, penelitian ini bertujuan untuk memberikan informasi mengenai algoritma yang sesuai bagi prediksi atau klasifikasi kelulusan mahasiswa dari mata kuliah tersebut maupun mata kuliah lainnya. Analisis yang digunakan adalah kuantitatif dengan metodologi KNN dan SVM tersebut. KNN lebih unggul dari SVM berdasarkan penilaian dari beberapa parameter, sedangkan SVM lebih baik dari KNN dalam mendapatkan nilai ambang kelulusan.
\end{abstract}

Kata Kunci : SVM, KNN, kelulusan, klasifikasi, kuantitatif.

\begin{abstract}
Two different algorithms will use different approaches. Like KNN (K-Nearest Neighbour) and SVM (Support Vector Machine), with the former calculates the closest distance between two instances, while the latter calculates the existence of hyperplane that separates two resulted classes. By using train data consisting of anomaly or noise data and using real measurement normally given by a lecturer to the students in the class to determine the students' pass or fail in one subject, the research finds the difference between the two algorithms. The research is conducted in the University of XYZ on IIT (Introduction to Information Technology) subject. With the use of Orange Data Mining software, the research aims to give information about the suited algorithm for prediction or classification of student's success in a related subject or others. It uses quantitative analysis with KNN dan SVM algorithms methods. Based on an assessment of several parameters, KNN is better than SVM, but SVM is better than KNN in obtaining a passing threshold value.
\end{abstract}

Keywords : SVM, KNN, success, classification, quantitative

\section{PENDAHULUAN}

Universitas yang berkualitas tidak mesti mahal, namun kualitas pendidik yang secara konstan dan kontinu ditingkatkan, seperti meningkatkan kedisiplinan mengajar, melakukan riset yang berkelanjutan, memberikan pelayanan mendidik yang baik serta pemberian program beasiswa yang terorganisir, dapat menjadi faktor penting bagi penentuan kualitas suatu universitas. Penelitian dilakukan pada Jurusan Teknik Informatika Fakultas Teknologi dan Ilmu Komputer dari Universitas XYZ untuk mata kuliah Pengantar Teknologi Informasi. Jurusan dimana suatu mata 
kuliahnya diampu oleh lebih dari 11 orang dosen ini membutuhkan kondisi komunikasi yang sangat baik antar sesama dosen pengampu, untuk menjamin keseragaman kualitas pendidikan.

Dengan bantuan Software Orange Data Mining, penelitian ini bertujuan untuk memberikan informasi mengenai algoritma yang sesuai bagi prediksi atau klasifikasi kelulusan mahasiswa dari mata kuliah tersebut maupun mata kuliah lainnya. Dengan menggunakan data train yang memiliki beberapa data anomali atau noise, berdasarkan penilaian nyata di lapangan yang umumnya diberikan dosen kepada mahasiswa terhadap hasil lulus atau tidak lulus dari suatu mata kuliah, diharapkan penelitian ini mendapatkan pembeda antara dua algoritma, yaitu KNN (K-Nearest Neighbour) dan SVM (Support Vector Machine).

Sedangkan manfaat dari penelitian ini adalah memberikan gambaran pola kelulusan yang berkaitan dengan penilaian mahasiswa terhadap mata kuliah tersebut maupun mata kuliah lainnya. Disamping itu juga memberikan masukan dalam mengantisipasi mahasiswa yang dalam mengikuti perkuliahan menunjukkan gejala yang tidak sesuai dengan target kelulusan.

Algoritma K-Nearest Neighbour merupakan metode klasifikasi yang sudah diklasifikasikan sebelumnya, dimana hasil query instance yang baru diklasifikasikan berdasarkan mayoritas kedekatan jarak dari kategori yang ada [1].

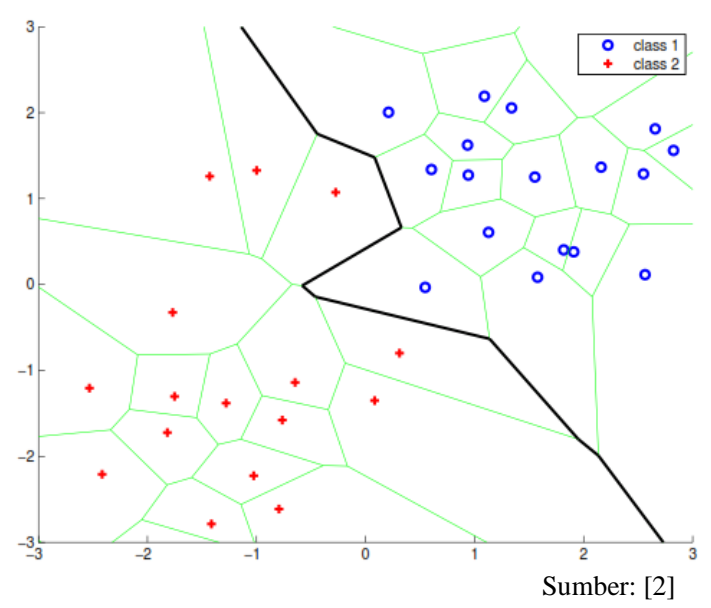

Gambar 1. Batas Keputusan dari Dua Kelas di KNN

Jarak dihitung dengan menggunakan rumus euclidean distance, yaitu rumus phytagoras dengan lebih dari dua dimensi [3], [4].

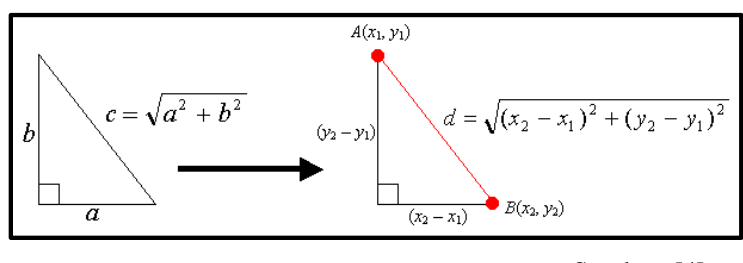

Sumber: [4]

Gambar 2. Rumus Phytagoras

Kemudian diperoleh rumus euclidean distance sebagai berikut:

$$
\begin{aligned}
d & =\sqrt{\left(q_{1}-p_{1}\right)^{2}+\left(q_{2}-p_{2}\right)^{2}+\cdots+\left(q_{n}-p_{n}\right)^{2}} \\
& =\sqrt{\sum_{i=1}^{n}\left(q_{i}-p_{i}\right)^{2}}
\end{aligned}
$$

dimana:

$q_{i}$ dan $p_{i}$ : merupakan jarak antar dua titik ke $i$

Sedangkan algoritma SVM (Support Vector Machine) merupakan metode dalam Supervised Learning yang digunakan untuk mencari hyperplane terbaik dengan memaksimalkan jarak antar kelas [5]. 


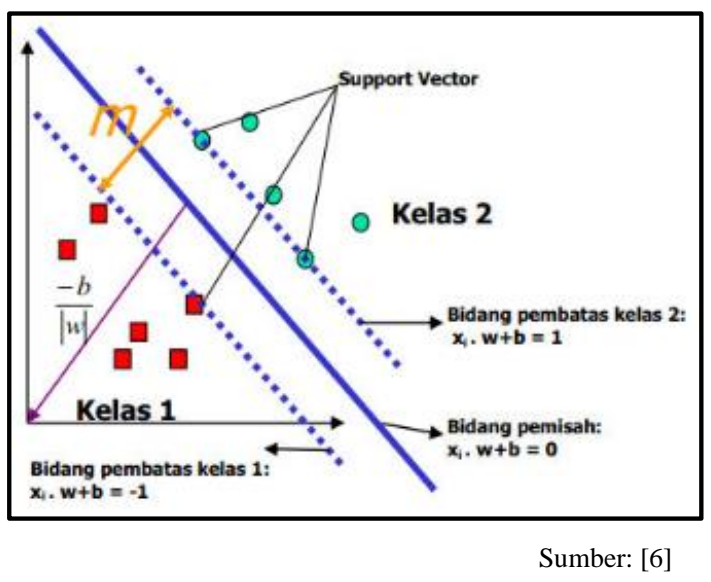

Gambar 3. Ilustrasi SVM

Jarak antara dua support lines dituliskan dalam persamaan berikut:

$$
\begin{aligned}
& \max _{w, b} \frac{2}{\|w\|} \\
& (w \cdot x)+b \geqslant 1, \quad \forall_{i}: y_{i}=1 \\
& (w \cdot x)+b \leqslant-1, \forall_{i}: y_{i}=-1
\end{aligned}
$$

dimana:

max : jarak maximum antar dua garis $w, b$

$w, x, b$ dan $y$ : komponen dari persamaan garis lurus

Klasifikasi biner adalah model statistik yang membagi kumpulan data menjadi dua kelompok, yaitu positif dan negatif, seperti yang dapat dilihat pada tabel confusion matrix.

Tabel 1. Confusion Matrix

\begin{tabular}{|l|l|l|}
\hline \multirow{2}{*}{ Aktual } & \multicolumn{2}{|c|}{ Prediksi } \\
\cline { 2 - 3 } & \multicolumn{1}{|c|}{ Positive } & Negative \\
\hline Positive & True Positive (TP) & False Positive (FP) \\
\hline Negative & False Negative (FN) & True Negative (TN) \\
\hline
\end{tabular}

Sumber: [7]

Performance yang masuk dalam tahapan evaluasi dapat dilakukan dengan menghitung akurasi, error dan ROC (Receiver Operating Characteristic) dengan melihat AUC (Area Under Curve) nya [8] dimana nilai AUC lebih besar maka berarti nilainya akan lebih baik.

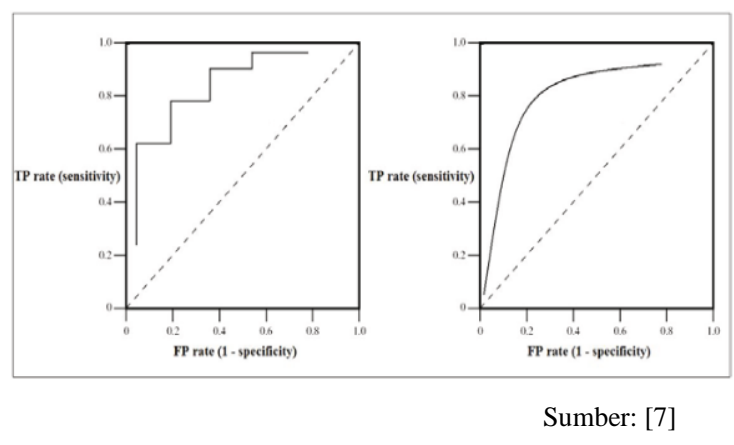

\section{Gambar 4. Kurva ROC untuk Kasus Diskrit dan Kontinu}

Sedangkan rumusan akurasi dan error adalah sebagai berikut:

$$
\begin{aligned}
\text { Akurasi } & =\frac{T P+T N}{T P+T N+F P+F N} \\
\text { error } & =\frac{F P+F N}{T P+T N+F P+F N}
\end{aligned}
$$

\section{METODE PENELITIAN}

Penelitian ini menggunakan metodologi KNN (K-Nearest Neighbour) dan SVM (Support Vector Machine) sebagai algoritma penyelesaian masalah berdasarkan jarak dan penentuan hyperplane. Sedangkan metode yang digunakan adalah analisis kuantitatif. Analisis kuantitatif merupakan penelitian yang didasarkan kepada angka-angka atau penghitungan kuantitas terhadap semua fenomena yang berkaitan dengan numerik [9]. Adapun jumlah populasi yang diambil adalah sebanyak 175 mahasiswa yang mengikuti kuliah Pengantar Teknologi Informasi. Parameter input yang diambil adalah tugas (HomeWork), ujian tengah semester (MidTest) dan ujian akhir semester (FinalTest). Informasi dari nilai yang diperoleh dikategorikan menjadi:

1. 0 - <56, menyatakan tidak lulus

2. $>=56$, menyatakan lulus

Langkah-langkah penggunaan metode KNN (K-Nearest Neighbour) adalah sebagai berikut [10]: 
1. Tentukan nilai $\mathrm{K}$

2. Hitung jarak data baru ke setiap label data.

3. Tentukan $k$ labeled data yang mempunyai jarak yang paling minimal

4. Klasifikasikan data baru ke dalam label data yang mayoritas KNN dipilih berdasarkan matrik jarak

Sedangkan secara umum cara kerja SVM adalah dengan menemukan jarak terjauh dari hyperplane terhadap dua kelas. Proses penentuannya dilakukan berulang kali hingga menemukan hyperplane terbaik.

\section{HASIL DAN PEMBAHASAN}

Penelitian ini menggunakan 175 data mahasiswa yang diklasifikasikan ke dalam dua kelas, yaitu lulus (Passed) dan tidak lulus (Failed) di Universitas XYZ. Universitas ini menekankan kepada para dosen untuk mengajarkan tidak hanya hard-skill tapi juga soft-skill kepada para mahasiswa, sehingga keahlian yang didapat setelah lulus nantinya akan lebih lengkap. Oleh karena itu aktifitas seperti keaktifan di kelas maupun kuis menjadi faktor penilaian yang diikut sertakan pada penelitian ini.

Beberapa kriteria penilaian yang umum dilakukan pada kelulusan mahasiswa dalam suatu mata kuliah mencakup keseluruhan nilai dari kehadiran, tugas, ujian tengah semester, ujian akhir semester serta nilai-nilai penunjang lainnya seperti keaktifan di kelas dan kuis, dengan rincian sebagai berikut:

1. Nilai akhir harus mencapai nilai lebih besar atau sama dengan 56

2. Absensi harus memenuhi setidaknya 80 persen

3. Nilai tugas minimal 60

4. Menghadiri kuis yang diadakan

5. Aktif di kelas dengan bertanya atau menjawab pertanyaan-pertanyaan yang terlontar di kelas baik yang dikemukakan oleh dosen maupun mahasiswa pada sesi diskusi

Namun demikian, beberapa penilaian subyektif dapat saja terjadi dengan anggapan bahwa seorang mahasiswa mungkin lengah pada saat ujian, padahal dalam kegiatan belajar mengajar seharihari di kelas dosen melihat bahwa mahasiswa tersebut memiliki potensi yang cukup besar di perkuliahan tersebut. Berikut beberapa contoh yang mungkin terjadi dalam hal pemberian penilaian di kelas, yaitu:

1. Memenuhi nilai total minimum namun absensi kurang dari 80 persen, sehigga keputusan kelulusan dilihat pada nilai tugas yang tinggi, seperti lebih besar atau sama dengan 90

2. Memenuhi nilai total minimum namun absensi kurang dari 80 persen, sehingga keputusan kelulusan dilihat pada nilai keaktifan yang tinggi, seperti lebih dari 3 kali dalam mengajukan pertanyaan maupun menjawab, ditambah dengan selalu menghadiri kuis yang diadakan di kelas

Nilai tugas biasanya mencakup beberapa nilai berikut ini:

1. Nilai absensi

Memberikan nilai dengan porsi 50 persen dari nilai tugas bila mahasiswa menghadiri seluruh perkuliahan yang biasanya berkisar sekitar 14 kali pertemuan

2. Nilai keaktifan di kelas

Biasanya dosen akan memberikan porsi hingga 30 persen dari nilai tugas bila mahasiswa aktif hingga bertanya atau menjawab sebanyak lebih dari atau sama dengan 3 kali

3. Nilai kuis

Nilai dengan porsi hingga 20 persen dari nilai tugas akan diberikan bila mahasiswa mendapatkan nilai yang sangat memuaskan dari soal yang diberikan 
Dengan mendapatkan nilai tugas dalam penelitian ini, diasumsikan bahwa ketiga penilaian tersebut di atas sudah terwakili dengan baik sehingga diharapkan dapat memberikan nilai output yang cenderung akurat.

Adapun atribut yang digunakan sebagai evidence, baik dalam Algoritma SVM maupun KNN pada penelitian ini, terdiri dari 3 item, yaitu.

1. Nilai tugas

2. Nilai ujian tengah semester

3. Nilai akhir semester

Dengan berbagai anomali atau noises yang ada, penelitian ini berusaha untuk melihat hasil perbandingan terbaik antara kedua algoritma, yaitu SVM dan KNN. Pengerjaan pengolahan data dilakukan dengan bantuan software data mining yang mengikuti karakteristik dari masingmasing algoritma. Beberapa contoh kedua klasifikasi data dapat dilihat berikut ini.

Tabel 2. Data Training yang Menyatakan Mahasiswa Lulus

\begin{tabular}{|r|l|r|r|r|l|}
\hline No & Name & Homework & MidTest & FinalTest & Result \\
\hline 1 & Irfan N C & 90 & 90 & 70 & Passed \\
\hline 2 & Anggi P & 90 & 95 & 61 & Passed \\
\hline 3 & Akram A & 90 & 72 & 60 & Passed \\
\hline 4 & Anastasya T & 90 & 85 & 72 & Passed \\
\hline 8 & Luthfi R & 100 & 85 & 34 & Passed \\
\hline 10 & Rini H & 90 & 85 & 70 & Passed \\
\hline 12 & Ananda M P & 90 & 85 & 75 & Passed \\
\hline 15 & Abdul A & 100 & 80 & 53 & Passed \\
\hline 17 & Ismuari S & 100 & 76 & 47 & Passed \\
\hline 18 & Dimas C K & 100 & 80 & 58 & Passed \\
\hline 19 & M Subhan R & 80 & 95 & 66 & Passed \\
\hline 20 & Savira S & 90 & 80 & 61 & Passed \\
\hline 22 & Nur Imama & 90 & 80 & 72 & Passed \\
\hline 23 & Asyraf A K U & 90 & 80 & 55 & Passed \\
\hline 24 & Ega Ratna D P & 100 & 85 & 87 & Passed \\
\hline 25 & Gardika A S & 90 & 80 & 71 & Passed \\
\hline 26 & Humayra H A & 100 & 76 & 90 & Passed \\
\hline 27 & Ibrahim A & 100 & 85 & 81 & Passed \\
\hline 28 & Ade Rian & 100 & 95 & 40 & Passed \\
\hline 29 & Miftahul R & 90 & 90 & 67 & Passed \\
\hline
\end{tabular}

Tabel 3. Data Training yang Menyatakan Mahasiswa Tidak Lulus

\begin{tabular}{|r|l|r|r|r|l|}
\hline No & Name & Homework & MidTest & FinalTest & Result \\
\hline 5 & M Nursyamsi & 90 & 50 & 28 & Failed \\
\hline 6 & Sapta S Y & 90 & 45 & 17 & Failed \\
\hline 7 & M Ryansah & 0 & 30 & 0 & Failed \\
\hline 9 & Apriadi S & 100 & 30 & 10 & Failed \\
\hline 11 & M Afitra P & 0 & 0 & 0 & Failed \\
\hline 13 & Liftiana N S & 100 & 50 & 18 & Failed \\
\hline 14 & Maher F S & 80 & 50 & 18 & Failed \\
\hline 16 & Bima N S & 90 & 30 & 42 & Failed \\
\hline 21 & Angga E & 0 & 0 & 0 & Failed \\
\hline 35 & Lukaslie & 0 & 68 & 0 & Failed \\
\hline 36 & Adelia F & 90 & 62 & 28 & Failed \\
\hline 37 & Ibnu H & 80 & 62 & 9 & Failed \\
\hline 39 & Deri D & 90 & 50 & 21 & Failed \\
\hline 45 & Bintang S R & 15 & 45 & 81 & Failed \\
\hline 46 & Sugeng R & 15 & 68 & 68 & Failed \\
\hline 47 & Rita B & 15 & 72 & 82 & Failed \\
\hline 49 & Laberta R & 15 & 90 & 35 & Failed \\
\hline 50 & Rayindra D & 15 & 85 & 56 & Failed \\
\hline 53 & Haris F A L & 0 & 0 & 0 & Failed \\
\hline 57 & Nadia A S & 80 & 80 & 60 & Failed \\
\hline & & & & Sumber: Penulis \\
\hline
\end{tabular}

Pada penggunaan metodologi SVM, dilakukan pemetaan pada Software Orange Data Mining sehingga diperoleh peta grafiknya sebagai berikut.

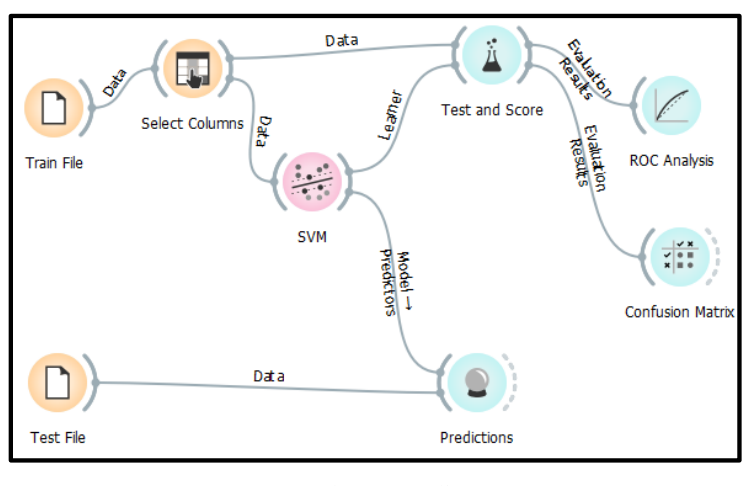

Sumber: Penulis

\section{Gambar 5. Peta SVM Pada Orange Data Mining}

Dari peta grafik tersebut, dapat diperoleh grafik ROCnya dengan cara menampilkan pilihan ROC analysis pada software tersebut. 


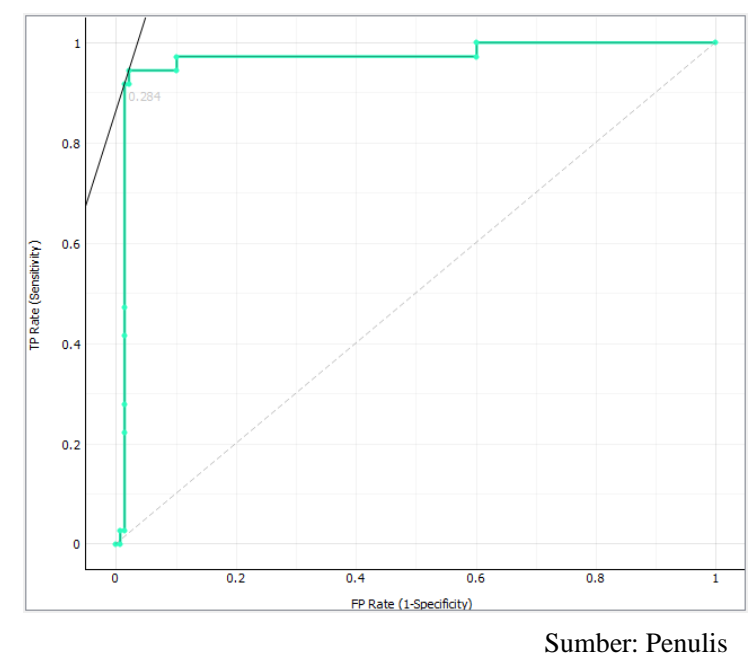

Gambar 6. Grafik ROC untuk SVM

Dari grafik tersebut diperoleh nilai AUC sebesar 0,966. Kemudian nilai akurasi dan error dapat dihitung sebagai berikut:

$$
\begin{gathered}
\text { Akurasi }=\frac{137+30}{137+30+2+6}=0,954286 \\
\text { error }=\frac{2+6}{137+30+2+6}=0,045714
\end{gathered}
$$

Dari kedua hasil perhitungan di atas, nampak bahwa akurasi penggunaan metodologi SVM tergolong sangat tinggi dengan nilai error yang sangat rendah. Kemudian dari semua nilai parameter yang diperoleh, dilakukan pengujian dengan menggunakan beberapa data test sehingga diperoleh hasil sebagai berikut:

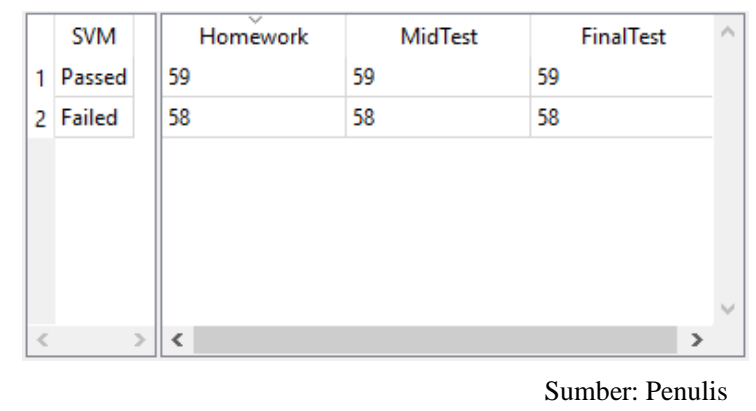

\section{Gambar 7. Hasil Pengujian SVM pada Orange Data Mining}

Nilai 58 dan 59 menjadi nilai batas kelulusan dari pengujian yang dilakukan. Kedua nilai tersebut sudah cukup mendekati harapan dari nilai kelulusan standar.

Sedangkan pada penggunaan metodologi KNN, pemetaan pada Software Orange Data Mining dilakukan sebagai berikut:

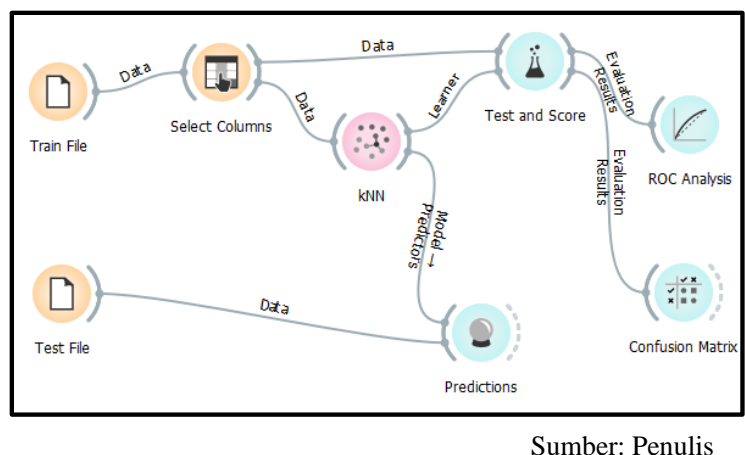

\section{Gambar 8. Peta KNN pada Orange Data Mining}

Dalam metodologi KNN, ada pemilihan jumlah pengclusteran (nilai $\mathrm{K}$ ) untuk mendapatkan nilai akurasi terbaik [11].

Tabel 4. Pembagian Cluster dan Nilai Akurasinya

\begin{tabular}{cr}
\hline Cluster & \multicolumn{1}{c}{ Akurasi } \\
\hline K1 & 0,96 \\
K2 & 0,96 \\
K3 & 0,954286 \\
K4 & 0,965714 \\
K5 & 0,948571 \\
\hline & Sumber: Penulis
\end{tabular}

Dari tabel tersebut dapat dilihat bahwa membagi data menjadi 4 kelompok $(K=4)$ memiliki nilai akurasi yang paling tinggi. Uraian dari nilai akurasi dan error dengan cluster tersebut dijabarkan berikut ini.

$$
\begin{gathered}
\text { Akurasi }=\frac{136+33}{136+33+3+3}=0,965714 \\
\text { error }=\frac{3+3}{136+33+3+3}=0,034286
\end{gathered}
$$

Nilai akurasi tersebut tergolong juga sangat tinggi dengan kategori nilai error yang sangat rendah. Sedangkan grafik ROCnya dapat dilihat pada gambar berikut ini. 


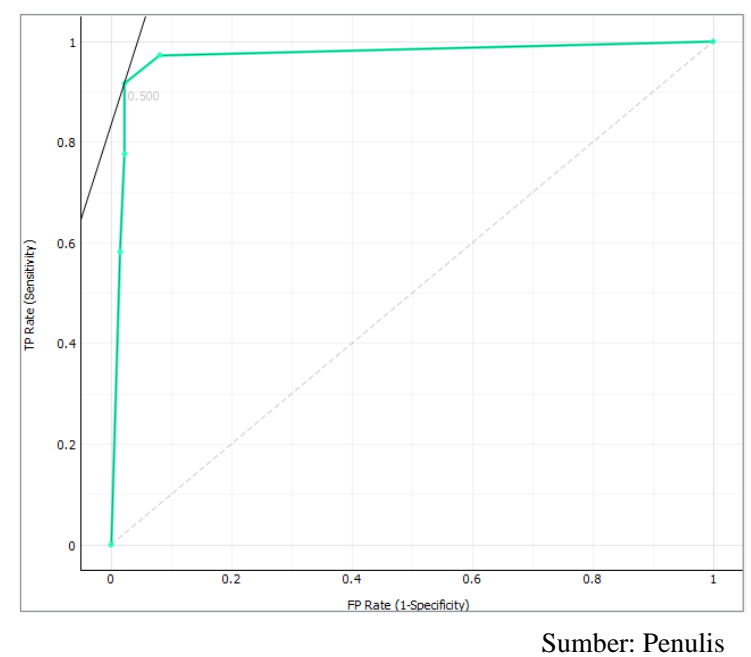

Gambar 9. Grafik ROC untuk KNN (K=4)

Dari grafik ROC tersebut diperoleh nilai AUC adalah sebesar 0,972. Kemudian dilakukan pengujian dengan beberapa nilai untuk mendapatkan nilai ambangnya sebagai berikut:

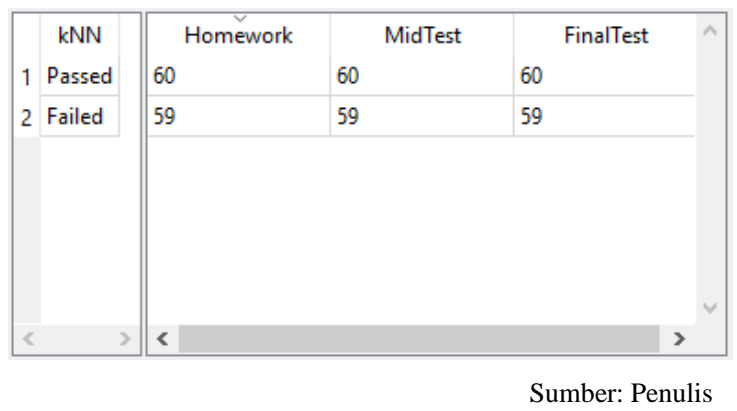

\section{Gambar 10. Hasil Pengujian KNN (K=4) pada Orange Data Mining}

Dari pengujian nampak bahwa nilai ambang kelulusan adalah pada nilai 59 dan 60 yang juga cukup dekat dengan nilai kelulusan yang diharapkan.

Hasil penelitian ini dapat dilihat dalam bentuk tabel berikut dimana beberapa poin perbandingan disandingkan.

Tabel 5. Perbandingan SVM dengan KNN $(\mathrm{K}=\mathbf{4})$

\begin{tabular}{|c|l|r|r|}
\hline No & \multicolumn{1}{|c|}{ Parameter } & \multicolumn{1}{c|}{ SVM } & \multicolumn{1}{|c|}{ KNN (K=4) } \\
\hline 1 & Nilai AUC & 0,966 & 0,972 \\
\hline 2 & Akurasi & 0,954286 & 0,965714 \\
\hline 3 & Error & 0,045714 & 0,034286 \\
\hline 4 & Nilai ambang kelulusan & $58-59$ & $59-60$ \\
\hline
\end{tabular}

\section{SIMPULAN}

Dari perbandingan di tabel 5, nilai AUC pada metodologi KNN lebih besar dari SVM, menunjukkan bahwa luas di bawah kurva ROC dari KNN besar yang mengartikan bahwa KNN lebih baik dari SVM. Demikian pulan dengan akurasi, dimana nilai KNN dengan jumlah cluster 4 lebih baik dari SVM. Untuk nilai errornya, KNN juga lebih baik dimana hal tersebut ditunjukkan dengan nilai error yang rendah yang berarti lebih kecil terjadi kesalahan penghitungan datanya. Sedangkan pada poin terakhir nilai dari metodologi SVM lebih baik dari KNN. Hal tersebut ditandai dengan nilai ambang lulus-tidak lulus dari SVM lebih mendekati harapan, yaitu nilai kelulusan sama dengan 56 dan di bawah nilai tersebut mahasiswa dinyatakan tidak lulus.

Dari hasil perbandingan terhadap empat poin penilaian, yaitu nilai AUC, akurasi, error dan nilai ambang kelulusan maka kesimpulan dapat diperoleh. Untuk tiga poin pertama dapat kita lihat bahwa untuk kasus pada penelitian ini KNN lebih unggul dari SVM. Namun untuk nilai ambang kelulusan SVM lebih baik dari KNN. Hal tersebut menunjukkan bahwa untuk kasus dalam penelitian ini, dimana terdapat beberapa data noise, KNN lebih baik dalam penilaian namun SVM memberikan hasil yang lebih sesuai dengan harapan.

\section{DAFTAR PUSTAKA}

[1] M. Kubat, "An Introduction to Machine Learning," An Introduction to Machine Learning. Springer International Publishing., pp. 1-348, 2017.

[2] A. Hertzmann and D. Fleet, "Machine Learning and Data Mining," 2012, p. 134.

[3] E. Alpaydin, "Introduction to Machine Learning, Second Edition," 
no. September. The Massachusetts Institute of Technology Press., 2010.

[4] A. M. Ismail, "Cara Kerja Algoritma k-Nearest Neighbour." , 2018. [Online]. Available: https://medium.com/bee-solutionpartners/cara-kerja-algoritma-knearest-neighbor-k-nn389297de543e

[5] N. Deng, Y. Tian, and C. Zang, "Support vector machines (SVM): Optimization Based Theory, Algorithms and Extension." CRC Press,Taylor \& Francis Group, 2013.

[6] F. S. Jumeilah, "Penerapan Support Vector Machine (SVM) untuk Pengkategorian Penelitian," Jurnal RESTI (Rekayasa Sistem dan Teknologi Informasi), vol. 1, no. 1. p. 19, 2017.

[7] S. Widaningsih, "Perbandingan Metode Data Mining Untuk Prediksi Nilai Dan Waktu Kelulusan Mahasiswa Prodi Teknik Informatika Dengan Algoritma C4,5, Naïve Bayes, Knn Dan Svm,"
Jurnal Tekno Insentif, vol. 13, no. 1. pp. 16-25, 2019.

[8] R. Arifin, "Memahami ROC dan AUC," 2019. [Online]. Available: https://medium.com/@arifinrio95/m emahami-roc-dan-auc2e0e4f3638bf.

[9] C. R. Kothari, Research Methodology, Methods \& Techniques, Second Rev. New Age International (P) Ltd., 2004.

[10] M. R. A. Nasution and M. Hayaty, "Perbandingan Akurasi dan Waktu Proses Algoritma K-NN dan SVM dalam Analisis Sentimen Twitter," Jurnal Informatika, vol. 6, no. 2. pp. 226-235, 2019.

[11] S. Aulia, S. Hadiyoso, and D. N. Ramadan, "Analisis Perbandingan KNN dengan SVM untuk Klasifikasi Penyakit Diabetes Retinopati berdasarkan Citra Eksudat dan Mikroaneurisma," ELKOMIKA: Jurnal Teknik Energi Elektrik, Teknik Telekomunikasi, \& Teknik Elektronika, vol. 3, no. 1. p. 75. 